\title{
ANALYSIS OF INFRASOUND PROPAGATION AT REGIONAL DISTANCE BY MINING EXPLOSION
}

\author{
Ch.Bayarsaikhan ${ }^{1}$, M.Ulziibat ${ }^{1}$, L.Tungalag ${ }^{1}$, Ch.Lkhagvajav $^{2}$, Alexis Le Pichon $^{3}$ \\ 1. MAS, RCAG Ulaanbaatar-51/152,Mongolia, ulzibat@rcag.ac.mn \\ 2. NUM,School of Physics and Electronics Ulaanbaatar-46/337,Mongolia \\ 3. CEA/DASE-LDG, BP128,91680 Bruyeres-le-Chatel,France
}

\begin{abstract}
ABSRACT
Seismic and acoustic recordings are particularly important to help identifying and locating industrial blasting sources. We have analyzed seismo-acoustic signals from mine blast for 2000 and 2005 in order to determine detection seismo-acoustic signals of explosion by seismic and infrasound stations. Several large mines in the region routinely generate explosions that are detected seismically and with infrasound. The mine range in distance from 40-500 km from the seismic, infrasound array. In last few years mining activity in Mongolia significantly increased. All events identified as quarry blasts have occurred during daytimes between 03:00 p.m. and 08:00 a.m. GMT and on weekdays from Monday to Friday. The corresponding number of infrasound detection is found to be dependent upon the regional weather condition, which is included air temperature, epicentral distance, wind force and velocity. We present the seismic and infrasound IMS stations and some results of analysis.
\end{abstract}

\section{First step: Characteristics of selected seismic explosions}

Baganuur coal mine is located around $145 \mathrm{~km}$ to the east of Ulaanbaatar. The active area of Baga-nuur mine covers an area of about 10 square $\mathrm{km}$ with $5 \mathrm{~km}$ long and $2 \mathrm{~km}$ wide area. The mine conducting relatively strong and permanent blasts over 5-50 tons. Blasting at mine is carried out in the open cast method, in deep surface excavations (boreholes). Ground truth information plays a critical role in the interpretation of signals and has included near-field observations from industrial blasts, blast design information for mine explosions and near-field observations of earthquakes. Combining design pattern information and near-source observations illustrates that peak amplitudes of regional seismic phases are greatly reduced from those expected for a contained single-fired explosion.

\section{Database assembly}

Waveforms from permanent stations in the region and ground truth information are being assembled into a database for subsequent convenient analysis. To date, ground truth information on about more than hundred events have been loaded into the database (Id, origin time, lat, lon, mag, depth, etc), including the following events from the Baganuur mine. 
(appendix 1) and (seismic station coordinate appendix 2).

The selected events surrounding the mine are listed in the table below. The closest station is UGDM at $62 \mathrm{~km}$ and the farthest listed in the table is IVGM at $130 \mathrm{~km}$.

Table 1

\section{Example of selected events}

\begin{tabular}{|c|c|c|c|c|c|c|c|c|c|c|}
\hline ID & JDATE & DD & MM & YY & Time & Min & Sec & LAT & LON & ML \\
\hline 131143 & 2003348 & 14 & 12 & 2003 & 3 & 34 & 44 & 47.783 & 108.568 & 2.96 \\
\hline 131182 & 2003350 & 16 & 12 & 2003 & 8 & 11 & 57 & 47.749 & 108.476 & 2.88 \\
\hline 131303 & 2003357 & 23 & 12 & 2003 & 8 & 41 & 11 & 47.683 & 108.462 & 2.39 \\
\hline 134788 & 2004040 & 9 & 2 & 2004 & 9 & 29 & 3 & 47.691 & 108.382 & 2.47 \\
\hline 141211 & 2004043 & 12 & 2 & 2004 & 6 & 52 & 32 & 47.708 & 108.395 & 2.09 \\
\hline 144765 & 2004071 & 11 & 3 & 2004 & 9 & 25 & 48 & 47.713 & 108.309 & 2.55 \\
\hline 144821 & 2004073 & 13 & 3 & 2004 & 8 & 59 & 39 & 47.721 & 108.296 & 2.55 \\
\hline 144824 & 2004073 & 13 & 3 & 2004 & 9 & 18 & 40 & 47.738 & 108.308 & 3.26 \\
\hline 145135 & 2004079 & 19 & 3 & 2004 & 9 & 20 & 42 & 47.711 & 108.344 & 2.39 \\
\hline 153180 & 2004161 & 9 & 6 & 2004 & 8 & 17 & 14 & 47.758 & 108.323 & 999. \\
\hline 154566 & 2004187 & 5 & 7 & 2004 & 8 & 21 & 53 & 47.731 & 108.357 & 999. \\
\hline 159749 & 2004223 & 10 & 8 & 2004 & 6 & 16 & 7 & 47.757 & 108.313 & 2.43 \\
\hline 161094 & 2004237 & 24 & 8 & 2004 & 1 & 27 & 35 & 47.738 & 108.390 & 2.21 \\
\hline 168943 & 2004296 & 22 & 10 & 2004 & 5 & 12 & 20 & 47.761 & 108.335 & 2.94 \\
\hline 168964 & 2004296 & 22 & 10 & 2004 & 9 & 42 & 30 & 47.758 & 108.330 & 2.55 \\
\hline 169171 & 2004300 & 26 & 10 & 2004 & 9 & 5 & 11 & 47.748 & 108.334 & 2.53 \\
\hline 169420 & 2004306 & 1 & 11 & 2004 & 9 & 50 & 51 & 47.730 & 108.338 & 1.57 \\
\hline 171920 & 2004343 & 8 & 12 & 2004 & 7 & 41 & 33 & 47.751 & 108.325 & 999. \\
\hline 131591 & 2004003 & 3 & 1 & 2004 & 9 & 8 & 32 & 47.55402 & 108.4223 & 2.29 \\
\hline 253957 & 2004002 & 2 & 1 & 2004 & 7 & 20 & 17 & 47.54581 & 108.3727 & 1.87 \\
\hline 255005 & 2004040 & 9 & 2 & 2004 & 8 & 56 & 3 & 47.725 & 108.389 & 2.25 \\
\hline 255006 & 2004040 & 9 & 2 & 2004 & 9 & 29 & 4 & 47.70528 & 108.589 & 2.45 \\
\hline 255007 & 2004043 & 12 & 2 & 2004 & 6 & 52 & 33 & 47.708 & 108.395 & 2.07 \\
\hline 255012 & 2004062 & 2 & 3 & 2004 & 8 & 23 & 45 & 47.685 & 108.323 & 1.60 \\
\hline
\end{tabular}




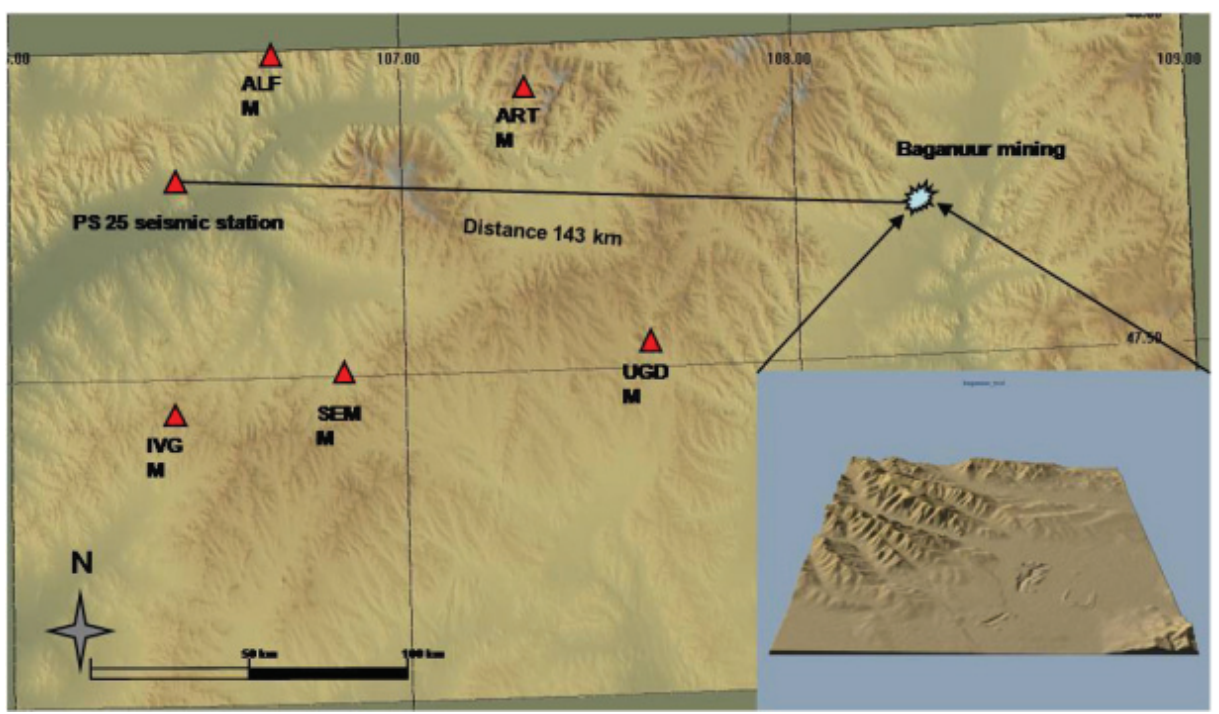

Figure 1 Location map of seismic station and Baganuur mining.

(The closest station UGDM at 62 км )

Broadband vertical records at around of Ulaanbaatar stations for of the Baganuur blasts are plotted in Fig 1. This simple display of the data illustrates three important characteristics of the data. First, the waveforms from single fired to another are very similar. This might be further investigated through a correlation analysis. Second, at this close range $(62 \mathrm{~km})$, the fundamental Rayleigh wave known as Rg has large amplitude. This secondary phase dominates the longer periods.

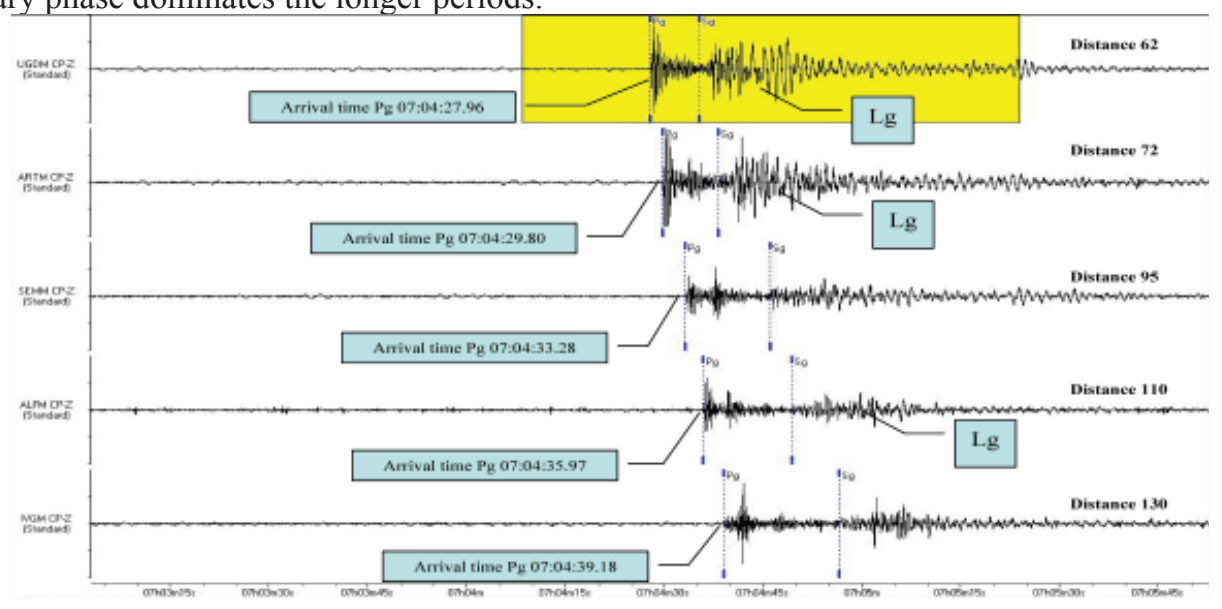

Figure 2. Vertical broadband seismic records of Baganuur quarry blasts (origin time 07:04:17.34) recorded at around Ulaanbaatar seismic stations $(62 \mathrm{~km})$. 
This result suggests that the quarry blast from Baganuur despite ranging in total explosive weight to nearly 5-50 tones may only be observed at near-regional distances. Fig 2

\section{Preliminary analysis and conclusion}

Timely cooperation with an active mine has proven that mining explosions records can be used to develop a data base of regional seismic signals from blasting. The key to this study has been the availability of blast records within 24 hours of the explosions. This information has then been used to assemble the set of all available seismic records using ONYX. A number of simple measurements on the waveforms developed during this study are presented to further illustrate the importance of the explosive source on the waveforms. This representation illustrates further the importance of Rayleigh waves at the longer periods. Even though the observations are only at $69 \mathrm{~km}$ one can also see the development of $\mathrm{Lg}$ in the 1-2 and 2-4 Hz band. Finally the relative importance of the P waves increases at the highest frequency band.

\section{Second step: Improvement of seismic location}

In 2000, RCAG has started a project to discriminate and separate quarry blast from seismic database. In frame of this project we have installed portable seismic and ground motion stations near the explosion areas around the Ulaanbaatar city. During this time we have succeed to record one event of Baga-nuur quarry blast with distance range between 500 and 800 meters from explosion point (explosion origin time 06:16:07.239, latitude 47.7542, longitude 108.3191). I illustrate location map of Baga-nuur, epicenter of blast area, mobile station and seismic records from some of the event in Fig 4.

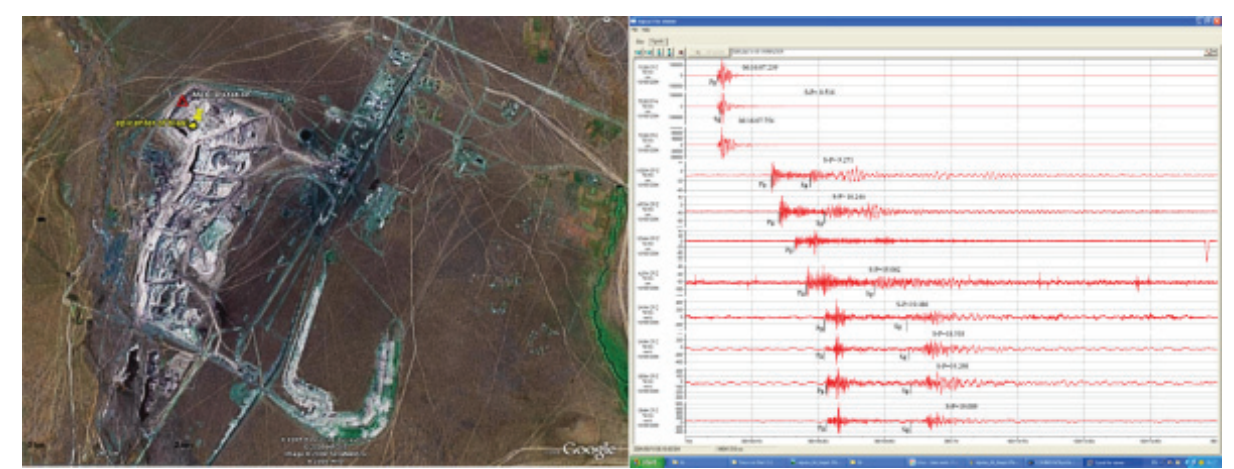

Figure 4 left location map of Baganuur blast point and mobile stations. Right seismic signals recorded during installation of portable short period seismic stations in (06:16:06.875). Station is located 500-800 meter from the source. Time difference between arrival time of $\mathrm{P}$ and $\mathrm{S}$ wave is 0.516 second. If we consider velocity of near surface $\mathrm{P}$ wave is equal 5.3 then can estimate origin time as 06:16:07.239.

As we see from this figure arrival time of Pg and $\mathrm{Sg}$ waves are less than one second which is shows very near distance records and also we can consider that onset of $\mathrm{P}$ wave is equal 
to the origin time of quarry blast.

Because, infrasound wave travels slow that will not be significant effect for the calculation of the celerity. On figure 6 shows instrument that we used during mobile station studies of active mining areas.

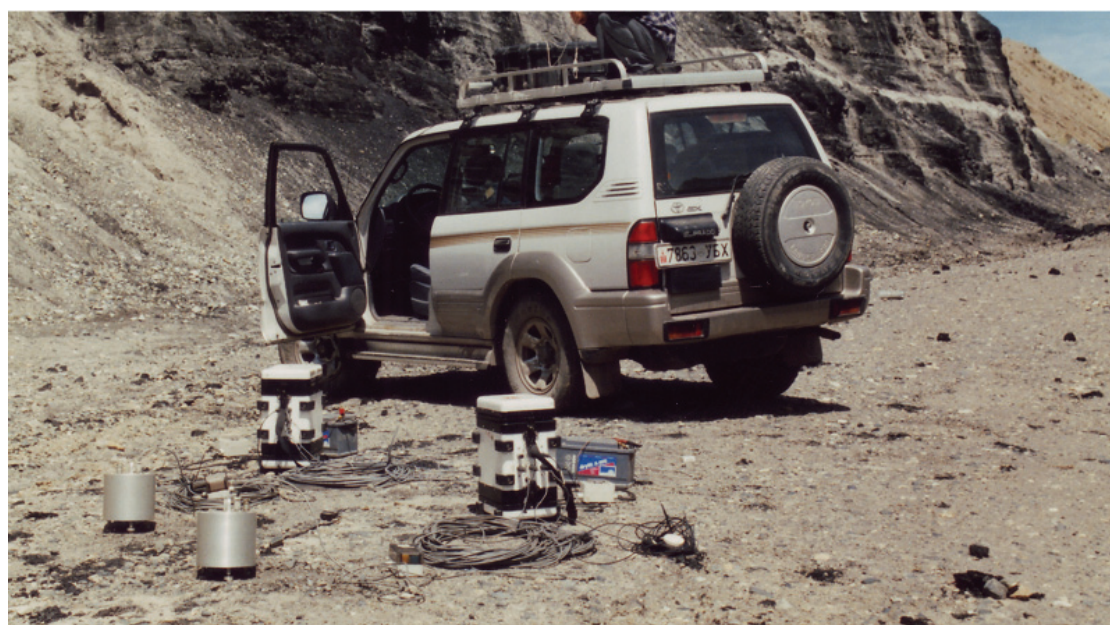

Figure 6. Seismic instrument we used for the mobile seismic station studies of active mining areas. On figure left site shown LC-4D short period 3 component geophone sensor with $1 \mathrm{~Hz}$ natural frequency. Digitizer is AIROI with 24 hours (12 megabit) on recording system.

Seismic phase picking and event selection procedure.

The waveform of cross-correlation techniques is one of powerful tools to determine relative location of aftershock or manmade ground thrust events. Is also high effective method to determine arrival times of same clusters event. In our case we used this techniques in order to determine quarry blasts in one location (or one cluster) and picking of $\mathrm{Pg}$ and $\mathrm{Lg}$ waves to determine precise origin times of blasting. Aim of to use this method is based to select one known quarry blasts (our case is recorded quarry blast during mobile seismic studies of active mining areas) then select and phase picking all common one cluster events by cross-correlating waveforms recorded in distance stations (our case PS $25+U B$ stations). After the selection and phase picking on applying master event techniques in order to estimate accurate origin time of selected quarry blasts.

Currently about more than 70 quarry blasts on the Baga-Nuur have been analyzed using cross-correlated Pn, Pg and Lg phases mostly recorded by PS25 seismic array (145 $\mathrm{km}$ from explosion) and UB seismic stations including ART ( $80 \mathrm{~km})$, UGDM (70 km), SEMM (92 km), ALFM (118 km). The several analyses and results of picking show below (Figure 7). All these cross-correlation measurements are done by manually and interactively by ONYX. 


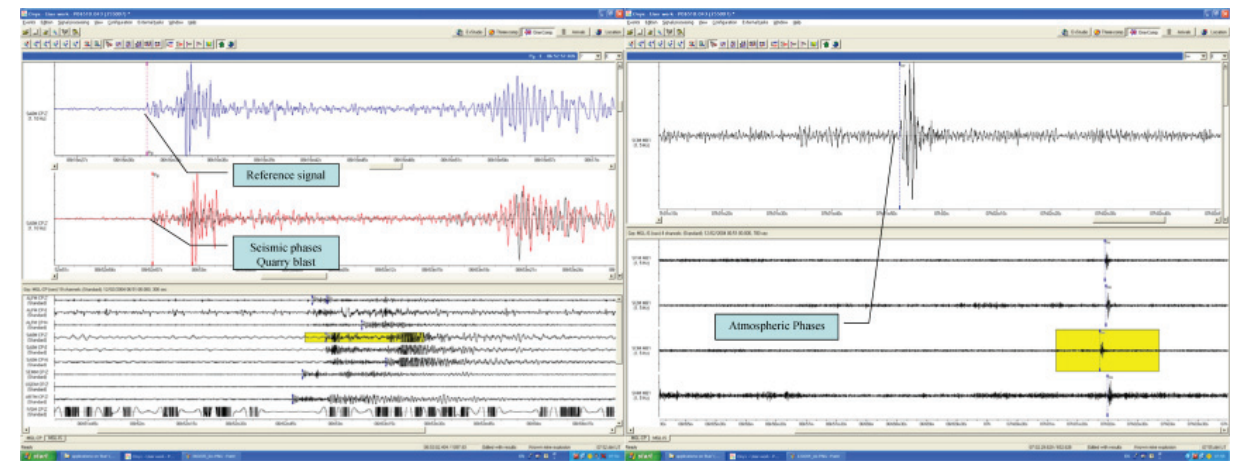

Figure 7. Measurement of cross correlation seismic phases and infrasound phase picking (12/02/2004 06:51:00.000) in seismic station of PS25 and infrasound station I34MN

\section{Master event Location analysis.}

As starting point for this section, note that the signal of quarry blast recorded during field measurement is selected as master event for this research. As we know precise position of explosion (measured by hand GPS with 4 meter horizontal error) and origin time by recording of near field observation then we can apply master event location analysis to determine origin time of quarry blasts that eventually detected on I34MN infrasound array. Before to apply to localization we have deployed to estimate work seismic velocity model of propagation path between this quarry blast site and stations. Our results are shows velocity of $\mathrm{P}$ and $\mathrm{S}$ wave smaller than our model which are using in ONYX. We estimate $5.3 \mathrm{~km} / \mathrm{sec}$ and $3.3 \mathrm{~km} / \mathrm{sec}$ respectively for the primary and secondary seismic phases. Fixing the epicenter and depth, ONYX was used to estimate the origin time and travel time residuals (relative to new estimated model) of each selected events.

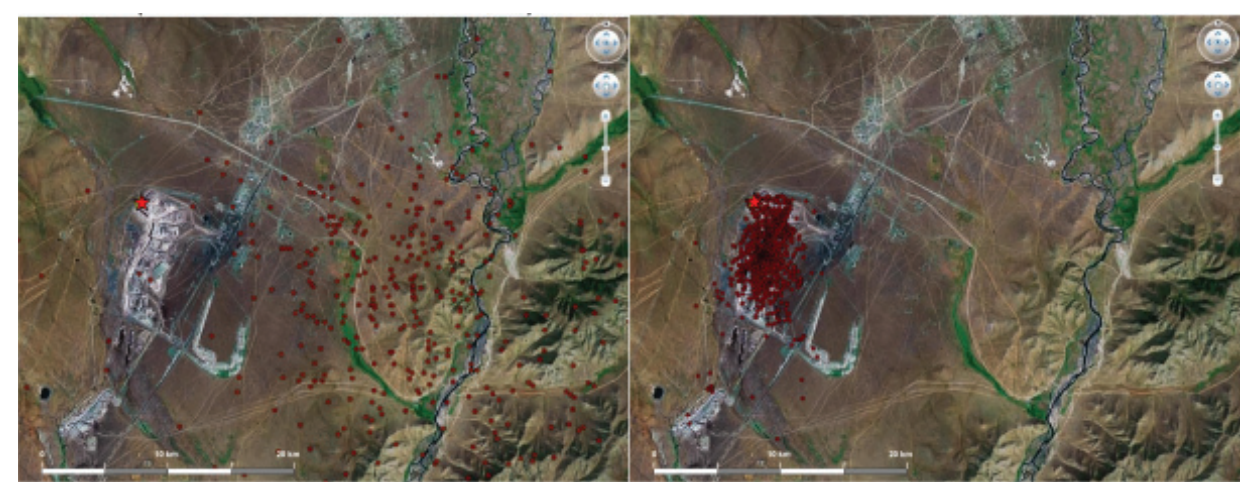

Figure 10 Left location before and right location after the relocation

We have relocated all ground thrusth events by using master event technique. Location of events much improved than before result and is show us that we can use these results for 
the determination of infrasound wave propagation. (Fig 10)

\section{Third step: Infrasound study}

The aim of this work is motivated by a need to understand atmospheric effect on infrasound wave propagation in short distance that is observed at infrasound array I34MN. Previous results of determination of infrasound propagation were generated by numerous quarry blasting areas around capital city Ulaanbaatar, was shown us robust observation of infrasonic waves in short distances.

As generally average atmospheric model predict no observation of infrasound waves until a distance range of several hundred kilometres. However, several researchers have reported infrasound detection in 50-250 km range indicating that seasonal winds may be necessary to these observations (Hagerty et al. 1999, Sorrel et al., 2000).

Our observation of first arrivals (some of them secondary arrivals) of infrasound wave are corresponds to the Is and Iw phases and is good match to the general infrasound velocity model, except of Baga-Nuur quarry blasting areas. The celerity of first arrival of infrasound propagation from this area calculated as lower $(0.25-0.28 \mathrm{~km} / \mathrm{sec})$ than we expected as is located about $141 \mathrm{~km}$ away from the I34MN array stations. This abnormal observation raised our interest to detail study on this region in order to understand how is related to the infrasound propagation path and atmospheric effect as this range is not fully understood from theory as typical infrasound propagation models.

\section{Research accomplished}

In this first part of research I more concentrated to show surety and accuracy of our estimation of travel time of infrasound phases. As we did on our previous study, all result of our estimation of infrasound celerity is based on the result of seismic localization. So it means our seismic result should be much precise that we can conclude this abnormal infrasound propagation produced by quarry blast of Baga-Nuur coal mining were located $120 \mathrm{~km}$ away from Ulaanbaatar ( $\sim 143 \mathrm{~km}$ from infrasound array).

One of best method to improve of location and origin time of quarry blast is to record by near distance portable seismic stations. That allow as to calibrate seismic travel times and thereby specially improve the estimation accuracy in this region. Then our approach is to have several seismic records of blasts in this region by very near distance, after select for relevant blasts by applying waveform cross-correlation in order to have one cluster events and accurate phase picking and master event location techniques to obtain precise origin times. After above estimation apply picking infrasound phases to determine of travel times and celerity.

\section{PMCC analyses for the Infrasound signals of each selected event.}

This is difficult to accomplish using seismic method alone to show seismic and infrasound detection is relevant for one source. Thus, in addition for the each selected event, must be run $\mathrm{PMCC}$ automated process in order to show that detected infrasound signals are propagated from our interested area by detecting azimuth and apparent velocity. Then before 
the estimate celerity of infrasound wave propagation we applied WinPMCC automatic analysis for each selected events in order to be sure that is relevant sources. Therefore, we have processed about 70 selected ground truth events of Baga-Nuur explosion area. First we calculated travel time of infrasound wave using global infrasound propagation model. After theoretical calculation of infrasound wave arrivals, prepared infrasound signals for each explosion considering with time duration before and after 240 second from theoretical arrival time. Then we applied WinPMCC analysis for each selected signals in order to detect all possible events. Our result shows there one permanent detected event with good azimuth respect to Baga-Nuur explosion area for all analyzed signals. These events are observing about 532 second after the first seismic arrival in SA0M station. Infrasound travel time of different explosions is varying between 510 and 560 second. But, most travel times are concentrated around $510-515$ and 565 second. Delay time of infrasound arrival from seismic arrival varying $490-535$ second. The result is showing Fig 11
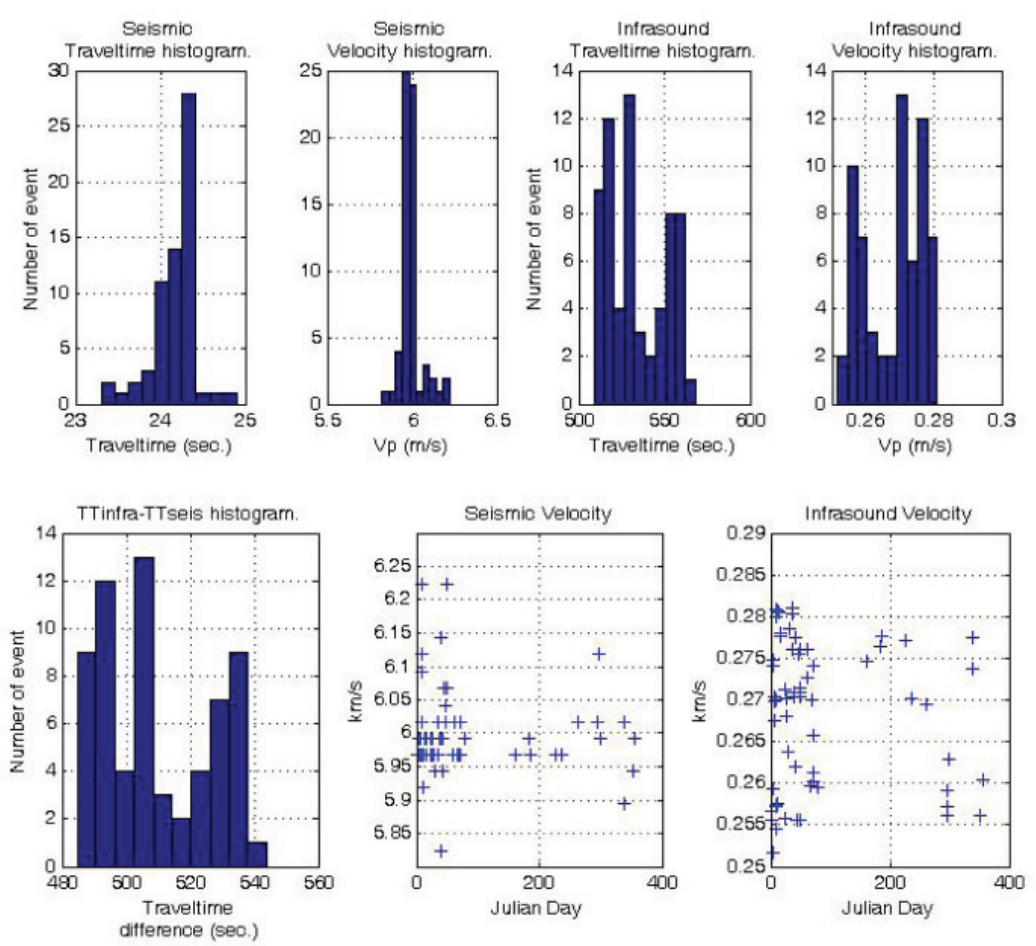

Figure 11 The Infrasound travel time of different explosions is varying) (Baganuur) 

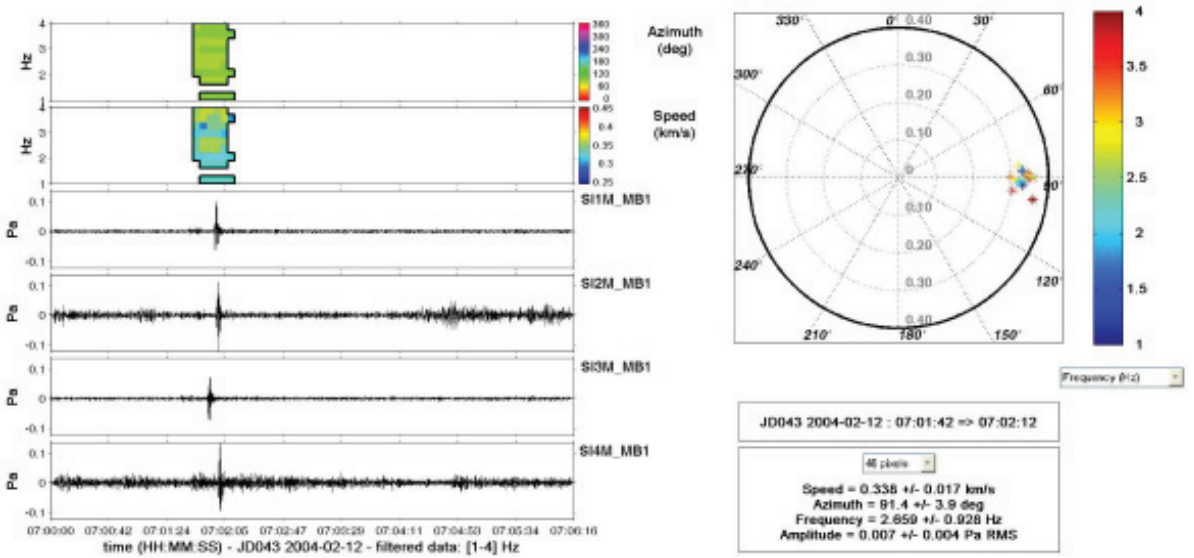

Figure 12. The result of above events using WinPMCC 2004-02-12 07:01:33

The celerity estimation and infrasound propagation analysis of Baga-Nuur quarry blasts.

Here we applied simple method to estimate celerity of infrasound phases as following:

$$
C=\frac{\Delta}{T p}
$$

C- celerity

$\Delta$ - epicentral distance between station to explosion

$\boldsymbol{T} \boldsymbol{p}$ - estimated travel time by using above method.

Using this simple formula we computed celerity for each station.

Table 5 and Fig 15 show result of our study that we applied to determine abnormal propagation of infrasound waves from Baganuur area were recorded I34MN array. The result is showing same result as our earlier studies. We found again low celerity an average of $\mathrm{C}$ $\sim 0.25-0.28$ which is corresponds to guided wave propagating between the lower troposphere and the ground (Mean celerity from [Brown, 2002]). But by generally average atmospheric model isn't return in such short distance (about $140 \mathrm{~km}$ ).

Figure 14 shows also instability of travel times of infrasound propagation much less connected due to wind effect of (troposphere Iw). Also we can observe seasonal variation as is clear for the warm and cold difference time. 

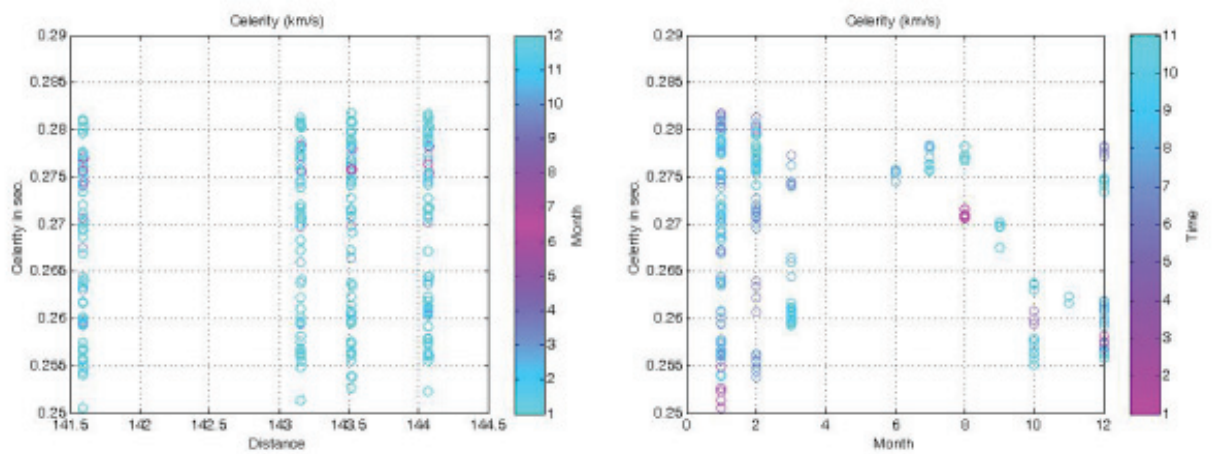

Figure 14. The celerity distribution of Baga-Nuur by distance and month.

\section{Discussion and Conclusion}

This study provides further confirmation that short-range sound propagation depends strongly on the atmospheric conditions, primarily on the variability of the meridional and zonal winds. In winter, infrasonic waves propagate both in the stratosphere and in the thermosphere sound channels. In summer, the propagation model explains only reflections in the thermosphere.

We compared all manual measurements of infrasound travel-time, celerity and azimuth from Baganuur, Erdenet, Sharyn gol, Shivee ovoo and Boroo mining sites at each month. The observed variation of about 50-100 seconds is mainly due to seasonal dependence of atmospheric wind characteristics

The wind direction of Mongolia dominates in direction NW-ES. The most windy season is during March to April in the Mongolia (reference). The number of recorded acoustic signals of quarry blast from mining sites of Baganuur, Erdenet, Boroo, and Sharyn gol is decreasing in spring associated with unfavorable wind direction during summer. On the contrary, the recorded acoustic signal of Shivee-Ovoo quarry blats is increasing in summer time during from June to September by corresponding decreasement of wind force and changement of wind direction

Many seismic and infrasonic signals are observed daily. Nearly a quarter of all seismic signals has associated infrasonic arrivals. Most of them occur during local working hours. These observations suggest that a great deal of the activity observed is man-made The seasonal dependence of travel time is mainly controlled by seasonal variations of atmospheric wind force and direction.

Almost all the first arrivals reached to Baganuur along the continental path are stratospheric return phases Is. In Baganuur celerity changes with the rate of 250-290 m/s which corresponds to stratospheric and thermospheric return phases $(I s-I t)$. Detection rate $(41.1 \%)$ is relatively consistent throughout the year and slightly low in summer variation by season. Which increased up to $290 \mathrm{~m} / \mathrm{s}$ in summer to $250 \mathrm{~m} / \mathrm{s}$ in winter. There were no predicted returns from the stratosphere when the propagation direction was against the predominant stratospheric winds. + 


\section{References}

Alcoverro, B. (1998). "Proposition d'un systeme de filtrage acoustique pourune station infrason IMS," CEA-DASE Scientific Report No. 241.

Bayarsaikhan. Ch${ }^{1}$, A. Le Pichon ${ }^{2}$, M. Ulziibat ${ }^{1}$., O.Sebe ${ }^{2}$ (2005) "Seismo-Acoustic data analysis at I34MN Mongolia "Infrasound Technology Workshop PAPEETE - TAHITI -FRENCH POLYNESIA NOVEMBER 28 - DECEMBER 2, 2005,

Brown, D. J., C. N. Katz, R. Le Bras, M. P. Flanagan, J. Wang, and A. K. Gault, Infrasonic signal detection and source location at the Prototype Data Centre, Pure Appl. Geophys., 159, 1081-1125, 2002.

Cansi, Y. (1995). "An automatic seismic event processing for detection and location: The PMCC method," Geophys. Res. Lett. 22, 1021-1024.

Cansi, Y. (1997). "An automated data processing method for mini-arrays," CSEM/EMSE European-Mediterranean Seismological Centre, NewsLetter 11, 1021-1024.

Donn.W.L, Rind.D (1972) "Microbaroms and the Temperature and Wind of the upper Atmosphere" Journal of atmospheric sciences. Vol 29: 158-159

Hedin, A.E. (1991). "Extension of the MSIS thermosphere model into the middle and lower atmosphere,” J. Geophys. Res. 96, 1159.

Le Pichon, A., and Cansi, Y. (1999). "One-year analysis of systematic detection and location of infrasounds in a prototype CTBT station,”Acustica 85, Suppl. 1!, 178.

Rind, D., Donn, W.L., and Dede, E. (1973). "Upper air wind speeds calculated from observations of natural infrasound,” J. Atmos. Sci. 30, 1726-1729.

Rind, D., and Donn, W.L. (1975). "Further use of natural infrasound as a continuous monitor of the upper atmosphere,” J. Atmos. Sci. 32, 1694-1704. 